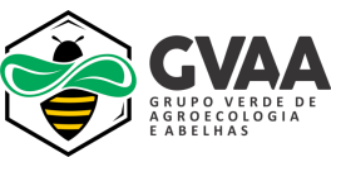

\title{
Taxa de decomposição foliar de espécies utilizadas em sistemas agroflorestais
}

\section{Foliar decomposition rate of species used in agroforestry systems}

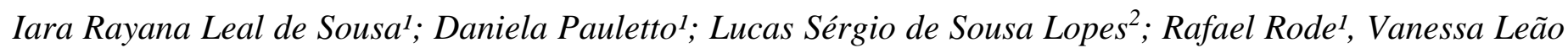 \\ Peleja ${ }^{I}$; Bruna Bandeira de Freitas ${ }^{1}$
}

${ }^{1}$ Universidade Federal do Oeste do Pará; ${ }^{2}$ Universidade Federal de Viçosa. rayana.iaraleal@gmail.com; danielapauletto@hotmail.com; lucaasergio@gmail.com; rafaelrode@gmail.com; peleja.floresta@gmail.com; bruna-bandeira@hotmail.com

\section{A R T I G O}

Recebido: 09/07/2019

Aprovado: 12/02/2020

Palavras-chave:

Serapilheira

Ciclagem de nutrientes

Adubação verde

Coeficiente de decomposição

Key words:

Burlap

Nutrient cycling

Green adubation

Decomposition coeficiente

\section{R E S U M O}

Os sistemas agroflorestais (SAFs) promovem a sustentabilidade do agroecossistema através das interações energéticas e da ciclagem de nutrientes por meio da produção e decomposição de biomassa sobre o solo. O objetivo deste trabalho foi avaliar a decomposição foliar de espécies utilizadas na adubação verde e de interesse econômico em sistemas agroflorestais. O estudo foi realizado no SAF experimental da Universidade Federal do Oeste do Pará (UFOPA). Analisou-se a decomposição foliar de seis espécies, sendo cacau (Theobroma cacao L.), cumaru (Dipteryx odorata (Aubl.) Forsyth) e pimenta-do-reino (Piper nigrum L.) consideradas de interesse econômico e feijão-de-porco (Canavalia ensiformis (L.) DC.), gliricídia (Gliricidia sepium (Jacq.) Walp.) e guandú (Cajanus cajan (L.) Huth) consideradas espécies de adubação verde. Para acompanhar a decomposição, utilizou-se o método de litter bags com o experimento alocado nos períodos mais chuvoso e menos chuvoso. Os dados de massa foliar remanescente foram analisados estatisticamente pelo teste Tukey e ajustados por meio de equação não-linear para obtenção da constante de decomposição (k) e tempo de meia-vida $\left(\mathrm{t}_{1 / 2}\right)$. As espécies apontadas para adubação verde apresentaram as maiores de taxas de decomposição ao final do experimento, nas quais a gliricidia e feijão de porco obtiveram as maiores taxas. Dentre as espécies escolhidas por interesse econômico, a pimenta do reino apresentou retorno de nutrientes ao solo superiores as espécies cumaru e cacau. O período seco obteve perda de massa mais lenta que o período chuvoso.

\section{A B S T R A C T}

Agroforestry systems (SAFs) promote agro-ecosystem sustainability through energy interactions and nutrient cycling through the production and decomposition of biomass on the soil. The objective of this work was to evaluate the leaf decomposition of species used in green manure and economic interest in agroforestry systems. The study was carried out at the experimental SAF of the Federal University of Western Pará (UFOPA). Analyze a leaf decomposition of six species, being cocoa (Theobroma cacao L.), coumaru (Dipteryx odorata (Aubl.) Forsyth) and black pepper (Piper nigrum L.) pig (Canavalia ensiformis (L.) DC.) , gliricidia (Gliricidia sepium (Jacq.) Walp.) and pigeon pea (Cajanus cajan (L.) Huth) species of green manure. To follow the decomposition, use the sandbag method with avocado experiments in the rainiest and least rainy temperatures. The remaining leaf mass data were statistically analyzed by the Tukey test and adjusted using a non-linear equation to check the decomposition constant $(\mathrm{k})$ and half-life $\left(\mathrm{t}_{1 / 2}\right)$. As species indicated for green manure, they present the highest decomposition rates until the end of the experiment, in which gliricides and pig grains are obtained as the highest rates. Among the species chosen for economic interest, black pepper shows the return of nutrients to the upper soil such as cocoa and cocoa species. The dry season lost mass loss slower than the rainy season.

\author{
Revista Verde \\ ISSN 1981-8203 \\ Pombal, Paraíba, Brasil
}

v. 15, n.2, abr.-jun., p.118-126, 2020 doi: $10.18378 /$ rvads.v15i2.6734 


\section{INTRODUÇÃO}

Os sistemas agroflorestais (SAFs) são práticas de uso e manejo agrícola com a presença do componente arbóreo e/ou animal, de maneira simultânea ou sequencial, onde a composição de espécies busca maximizar a oferta de luz e nutrientes, tanto na escala horizontal quanto na vertical, assim como valores socioeconômicos (EWERT et al., 2016). As diversas possibilidades de diferentes tipos de consórcios e a versatilidade de um SAF, são possíveis ajustes à realidade de cada produtor, a partir das limitações e condições ambientais oferecidas pela região de implantação. As características da região, como o clima quente e úmido, com duas estações do ano bem definida e grande diversidade de espécies devem ser consideradas, principalmente visando a capacidade de adaptabilidade de cada espécie inserida no SAF (SOUSA; VIEIRA, 2017).

A proposta desses sistemas é a capacidade de possuírem sustentabilidade própria através de interações energéticas, ciclagem de nutrientes e biodiversidade do sistema. O mecanismo de decomposição se dá por meio da mineralização da biomassa que é resultado da ação de organismos decompositores, as características bioquímicas do material orgânico e as condições ambientais, como a umidade e a temperatura, que desempenham papel importante no processo de decomposição (CUNHA et al., 2018; BAUER et al., 2016).

Schumacher et al. (2013) e Barradas (2010) apontam que o aporte e a conversão da serapilheira são essenciais para manutenção das propriedades dos solos de florestas nativas e plantadas, além disso, a práticas de manejo como o uso de espécies eficientes para a deposição de nutrientes no solo através da decomposição da biomassa beneficia o sistema produtivo, reduz os custos de produção e contribui para o fortalecimento da agricultura familiar.

A serapilheira de um sistema agroflorestal é composta por materiais vegetais, tais como folhas, galhos, flores e sementes bem como restos e fezes de animais (caso haja esse componente inserido no arranjo do SAF). As folhas representam a maior parcela na serapilheira e apresentam concentração de nutrientes relativamente mais elevadas que os demais componentes, além de sua taxa de decomposição ser mais elevada que a dos galhos e outros materiais (COSTA et al., 2010; CABIANCHI, 2010).

A escolha das espécies para a composição de um arranjo de SAF é uma fase importante, por levar em consideração aspectos ecológicos e econômicos. A função das espécies arbóreas introduzidas nos SAFs vai além da prestação de serviços ambientais e da decomposição de matéria orgânica via serapilheira. Estas espécies também fazem parte do elemento produtivo responsável pela geração de renda ao comercializar os produtos madeireiros e não-madeireiros, como frutos, sementes e óleos que advém do sistema implantado e, por isso, são caracterizadas como espécies de interesse econômico (SOUZA et al., 2013; SOUZA; PIÑA-RODRIGUES, 2013).

Nesse contexto, consorciar essas espécies com outras pertencentes, usualmente, à família das leguminosas, por exemplo, por meio da prática conhecida como adubação verde, favorece o desenvolvimento das culturas de interesse econômico inseridas no SAF. De acordo com Souza et al. (2012) e Wutke et al. (2014), a adubação verde consiste em cultivar espécies vegetais que, após atingir seu desenvolvimento vegetativo, serão cortadas e sua fitomassa pode ser deixada sobre a superfície ou incorporada ao solo, tendo por finalidade o favorecimento do rendimento de outras culturas e ainda promover o aumento, preservação e/ou restauração da fertilidade e da produtividade do solo.

Contudo, é pertinente aliar a essa escolha as contribuições, além da econômica, que cada espécie irá agregar ao sistema, principalmente no que tange à ciclagem de nutrientes permitindo o máximo aproveitamento das espécies no local e promovendo com isso o seu melhoramento. Por isso, compreender a dinâmica dessa ciclagem e desenvolver estudos que abordem esses fatores podem influenciar positivamente nas decisões de manejo do SAF e nas escolhas que irão compor o sistema. Dessa forma, o objetivo deste trabalho foi avaliar a decomposição foliar de espécies utilizadas na adubação verde e de interesse econômico em sistemas agroflorestais.

\section{MATERIAL E MÉTODOS}

\section{Caracterização da área}

O presente estudo foi realizado em um sistema de produção agroflorestal inserido na Unidade Experimental de Campo (UEC) da Universidade Federal do Oeste do Pará (UFOPA), situada no km 37 da Rodovia Santarém/Curuá-Una (PA 370), sob as coordenadas $02^{\circ} 24^{\prime \prime} 52^{\prime \prime} \mathrm{S}$ e $54^{\circ} 42^{\prime \prime} 36^{\prime \prime} \mathrm{W}$, no município de Santarém, região oeste do estado do Pará.

O sistema possui 0,5 ha de plantio consorciado, foi implantado em março de 2016 e está dividido em dois blocos. Anteriormente ao SAF, a área era composta por uma capoeira e vegetação secundária com aproximadamente 10 anos de pousio. O preparo da área para plantio foi realizado por meio do corte da vegetação e decomposição dos resíduos sobre o solo. O manejo do sistema não utiliza herbicidas e consiste em realização periódica de podas, capina seletiva e roçagem semimecanizada para controle das plantas espontâneas.

A região apresenta clima tipo quente e úmido segundo a classificação de Köppen, com chuvas concentradas no primeiro semestre do ano, com temperatura média anual variando de 25 a $28{ }^{\circ} \mathrm{C}$, com umidade relativa média do ar de $86 \%$. A precipitação pluvial média anual é de $1.920 \mathrm{~mm}$, variando de $170 \mathrm{~mm} \mathrm{mês}^{-1}$ a 60 mm mês-1 (FERREIRA, 2011). Segundo IDESP (2014), os solos da região são considerados do tipo Latossolo Amarelo de texturas médias, argilosas e muito argilosas.

Os dados de precipitação pluvial do período em estudo foram obtidos através de monitoramento diário, com horário préestabelecido, realizado na fazenda experimental da Ufopa com o uso de pluviômetro em plástico rígido, com escala de 0 a 130 $\mathrm{mm}$. Já os dados de temperatura foram obtidos através do banco de dados do Instituto Nacional de Meteorologia, coletados pela Estação Meteorológica mais próxima da área experimental, localizada no município de Belterra.

\section{Decomposição da fração foliar}

$\mathrm{O}$ experimento foi conduzido em dois períodos, sendo período 1: abril a agosto de 2017 (período chuvoso e início do período seco) e período 2: setembro de 2017 a janeiro de 2018 (período seco e início do período chuvoso). Foram coletadas 
amostras de folhas de seis espécies utilizadas em sistemas agroflorestais (Tabela 1), sendo três espécies consideradas de interesse econômico e três espécies utilizadas como componentes de adubação verde. Para esta coleta, foi estabelecido o critério de apenas folhas maduras, considerando que estas seriam as próximas a entrarem em processo de senescência.

Tabela 1. Espécies utilizadas no estudo e sua função principal em um SAF

\begin{tabular}{|c|c|c|}
\hline $\begin{array}{l}\text { Nome } \\
\text { popular }\end{array}$ & Nome Científico & $\begin{array}{c}\text { Função principal } \\
\text { em SAF }\end{array}$ \\
\hline Cacau & Theobroma cacao (L.) & Econômico \\
\hline Cumaru & $\begin{array}{l}\text { Dipteryx odorata } \\
\text { (Aubl.) Forsyth f. }\end{array}$ & Econômico \\
\hline $\begin{array}{l}\text { Pimenta-do- } \\
\text { reino }\end{array}$ & Piper nigrum. (L.) & Econômico \\
\hline $\begin{array}{l}\text { Feijão-de- } \\
\text { porco }\end{array}$ & $\begin{array}{l}\text { Canavalia ensiformis } \\
\text { (L.) DC. }\end{array}$ & Adubação verde \\
\hline Gliricídia & $\begin{array}{c}\text { Gliricidia sepium } \\
\text { (Jacq.) Kunth ex Walp. }\end{array}$ & Adubação verde \\
\hline Guandú & $\begin{array}{c}\text { Cajanus cajan (L.) } \\
\text { Huth }\end{array}$ & Adubação verde \\
\hline
\end{tabular}

As amostras de fração foliar foram secas ao ar por cinco dias, com a finalidade de diminuir o excesso de umidade presente nas folhas, obtendo-se a massa seca inicial, sem causar interferência nas características naturais do material coletado e no processo de decomposição, pois a pré-secagem do material em estufa antes da instalação do experimento de decomposição pode influenciar em resultados de taxa de decomposição mais lenta nos meses iniciais de coleta.

Para estimar a taxa de decomposição, utilizou-se 96 bolsas de náilon (litter bags) com malha de 2 × 2 mm e dimensões de 20 x $20 \mathrm{~cm}$, onde foram alocados $20 \mathrm{~g}$ do material foliar de cada espécie previamente seco ao ar, seguindo as recomendações metodológicas propostas por Vieira et al. (2014) e Silva et al. (2014). A malha utilizada teve o propósito de permitir o acesso da mesofauna, bem como microrganismos do solo que estão inseridos no processo de decomposição natural de folhas. O mesmo delineamento foi reproduzido para o segundo período experimental (setembro de 2017 a janeiro de 2018).

Foi utilizado o delineamento experimental inteiramente casualizado, considerando cada espécie como um tratamento e quatro repetições a cada coleta. Os litter bags, devidamente identificados, foram distribuídos de forma aleatória sobre a superfície do solo do SAF, a fim de simular a queda natural das folhas ao solo, que forma a serapilheira. Os tempos de coleta foram fixados a cada 30, 60, 90 e 120 dias, retirando-se quatro bolsas por espécie avaliada a cada coleta. O tempo total de avaliação foi definido com base em estudos da literatura relacionada, que adotaram intervalos entre 120 e 180 dias (ROSSI et al., 2013). Após a coleta, o material foliar contido em cada bolsa foi triado manualmente, em que foram removidas partículas de solo e de possíveis organismos presos às folhas. Em seguida, as amostras foram submetidas à secagem em estufa a 65 ${ }^{\circ} \mathrm{C}$ até obter massa constante (SCORIZA et al., 2012; SOUTO et al., 2013). Posteriormente, o material foi pesado para obtenção do peso seco.

O coeficiente de decomposição (k) da fração foliar de cada espécie foi calculado a partir dos valores de massa remanescente obtidos a cada coleta ao longo dos quatro meses de estudo, os quais foram ajustados ao modelo exponencial recomendado por Thomas e Asakawa (1993), empregando-se o software STATISTICA $\odot$ V. 10.

$$
\mathrm{P}_{\mathrm{t}}=\mathrm{P}_{0} \cdot \mathrm{e}^{-\mathrm{k} . \mathrm{t}}
$$

Em que: $\mathrm{Pt}=$ peso seco remanescente da amostra após t dias; $\mathrm{P0}$ $=$ peso seco inicial, colocado nos sacos no tempo zero $(\mathrm{t}=0) ; \mathrm{t}=$ tempo em dias e $\mathrm{k}=$ constante de decomposição.

A fim de determinar a velocidade da decomposição em dias, calculou-se ainda, a partir da constante de decomposição (k), o tempo de meia-vida das folhas. Este valor é obtido por meio da linearização do modelo anterior, e seu resultado corresponde ao tempo requerido para que ocorra a decomposição de metade da quantidade inicial do material foliar analisado. Com isso, adotouse a equação:

$$
\mathrm{t}_{1 / 2}=\ln (2) / \mathrm{kt}_{1 / 2}=\frac{\ln (2)}{\mathrm{k}}
$$

Em que: $\mathrm{t} 1 / 2=$ tempo de meia-vida das folhas e $\mathrm{k}=$ constante de decomposição obtida a partir do ajuste do modelo não linear.

\section{Análise estatística}

Os dados da massa seca remanescente correspondentes a cada período de coleta foram submetidos à análise de variância $(p<0,05)$ e posteriormente ao teste Tukey à $5 \%$ de significância. Para estas análises, utilizou-se o software estatístico Action Stat $3^{\odot}$.

Realizou-se, ainda, análise de regressão, com o uso do software Microsoft Excel (c) (versão 2013), com o intuito de delinear o comportamento das curvas de decomposição das espécies, a partir dos resultados mensais de massa remanescente. Os critérios para a escolha dos melhores modelos de regressão foram maior $\mathrm{R}^{2}$ (coeficiente de determinação ajustado) e menor erro padrão.

\section{RESULTADOS E DISCUSSÃO}

A Figura 1 expressa as variações mensais de precipitação pluvial acumulada e temperatura ocorrida durante o período experimental. O período 1 (abril a agosto/2017), apresentou precipitação acumulada superior ao obtido no período 2 (setembro/2017 a janeiro/2018), porém ressalta-se que para o período 2 esse resultado só foi alcançado por conta da ocorrência dos picos de pluviosidade, 157 e $252 \mathrm{~mm}$, respectivamente, nos meses de dezembro e janeiro. Quanto à temperatura, os valores médios mensais variaram de 25,9 a $27,2{ }^{\circ} \mathrm{C}$ para o período 1 e de 27,5 a $26,5^{\circ} \mathrm{C}$ para o período 2 . Observa-se ainda que as menores médias de temperatura foram registradas nos meses com maior regime pluviométrico. Lopes et al. (2013) destacam que as variáveis climáticas de grande parte do estado do Pará apresentam pequenas alterações ao longo do ano, entretanto o índice pluviométrico demonstra que a região possui duas estações definidas, uma bastante chuvosa (inverno amazônico) e outra considerada seca (verão amazônico). 
Figura 1. Precipitação acumulada $(\mathrm{mm})$ e temperatura média $\left({ }^{\circ} \mathrm{C}\right)$ mensal durante o período experimental.

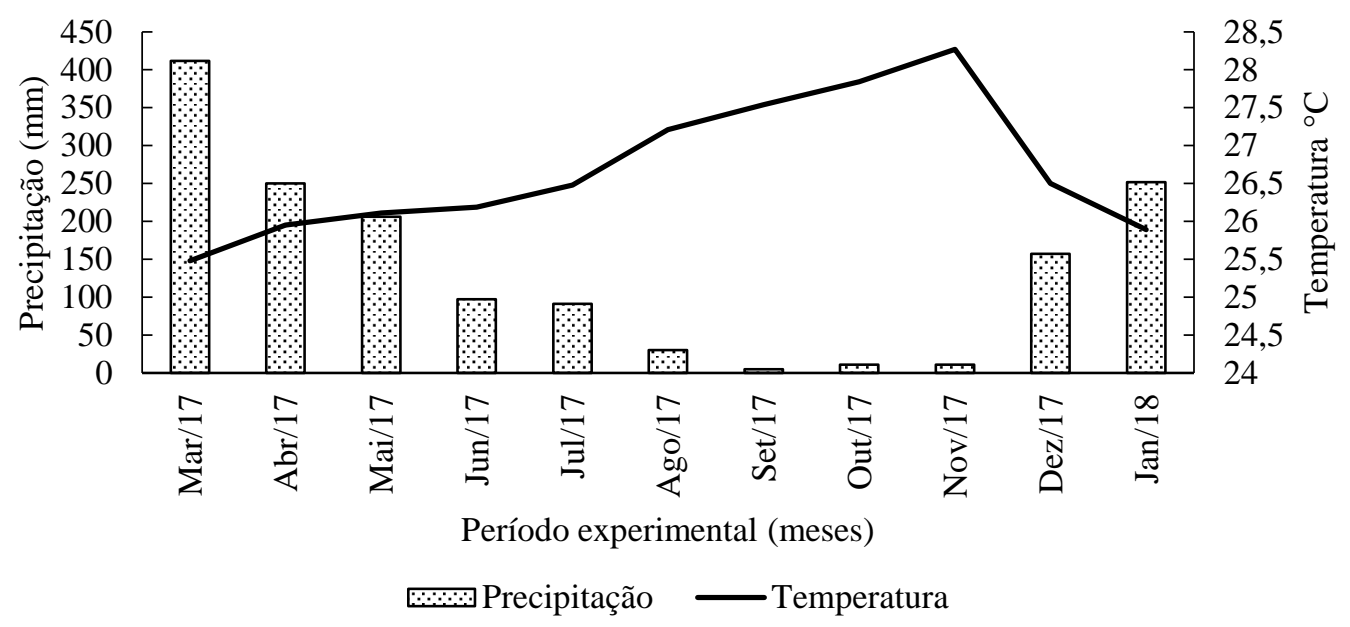

A Tabela 2 apresenta as médias de massa remanescente por espécie para cada tempo de coleta nos dois períodos de avaliação experimental, as espécies foram agrupadas de forma decrescente, em cada período, a partir da porcentagem total de massa decomposta ao final dos 120 dias de experimento. Observa-se que, durante o período 1 , as espécies apresentaram perda de massa de forma mais efetiva se comparada ao período 2 . O cacau e o cumaru foram as espécies que mais sofreram resistência ao processo de decomposição do tecido foliar (38,5 e 46,7 \%; 33,0 e $37,1 \%$ de perda ao longo de 120 dias nos períodos 1 e 2 respectivamente), sendo considerados estatisticamente iguais ao final do período de avaliação de cada experimento, isso pode ser explicado pela maior área foliar das espécies, assim como tecido vegetal mais resistente, dificultando a mineralização por parte dos micro-organismos decompositores. De acordo com Fontes (2006), as menores taxas de ciclagem biogeoquímica das folhas do cacaueiro podem ser devido às elevadas taxas de ciclagem bioquímica dessa espécie para $\mathrm{N}, \mathrm{P}$ e K, o que contribui para a baixa qualidade nutricional das folhas decíduas dessa e, consequentemente, menores taxas de mineralização.

Tabela 2. Massa remanescente (g) do processo de decomposição foliar das espécies em cada tempo e período de coleta e porcentagem final de massa decomposta.

\begin{tabular}{|c|c|c|c|c|c|c|c|c|c|}
\hline \multirow{2}{*}{ Espécies } & \multicolumn{8}{|c|}{ Tempo (dias) } & \multirow{2}{*}{$\begin{array}{c}\% \text { total de massa } \\
\text { decomposta }\end{array}$} \\
\hline & 30 & 0 & 6( & & 9 & & 12 & & \\
\hline \multicolumn{10}{|c|}{ Período 1 (abril a agosto) } \\
\hline Gliricidia sepium (Jacq.) Kunth ex Walp. & 6,8 & $\mathrm{~d}$ & 3,7 & $\mathrm{c}$ & 3,9 & $\mathrm{c}$ & 2,9 & $\mathrm{~d}$ & 85 \\
\hline Canavalia ensiformis (L.) DC. & 7,2 & $\mathrm{~d}$ & 4,9 & $\mathrm{c}$ & 3,1 & $\mathrm{c}$ & 3,4 & $\mathrm{~cd}$ & 83 \\
\hline Cajanus cajan (L.) Huth & 12,2 & $\mathrm{c}$ & 9,4 & $\mathrm{~b}$ & 8,6 & $\mathrm{~b}$ & 7,7 & $\mathrm{bc}$ & 62 \\
\hline Piper nigrum (L.) & 13,2 & bc & 10,5 & $\mathrm{~b}$ & 10,2 & $a b$ & 9,8 & $a b$ & 51 \\
\hline Dipteryx odorata (Aubl.) Forsyth f. & 15,8 & $\mathrm{a}$ & 12,1 & $a b$ & 12,7 & $\mathrm{a}$ & 10,7 & $a b$ & 47 \\
\hline Theobroma cacao (L.) & 14,7 & $\mathrm{ab}$ & 14,1 & $\mathrm{a}$ & 13,2 & $\mathrm{a}$ & 12,3 & $\mathrm{a}$ & 39 \\
\hline \multicolumn{10}{|c|}{ Período 2 (setembro a janeiro) } \\
\hline Canavalia ensiformis (L.) DC. & 11,7 & $\mathrm{~b}$ & 8,8 & $\mathrm{~b}$ & 8,8 & $\mathrm{bc}$ & 4,5 & $\mathrm{~b}$ & 77 \\
\hline Gliricidia sepium (Jacq.) Kunth ex Walp. & 17,8 & $\mathrm{a}$ & 14,4 & $\mathrm{a}$ & 7,1 & $\mathrm{c}$ & 4,8 & $\mathrm{~b}$ & 76 \\
\hline Cajanus cajan (L.) Huth & 16,6 & $a b$ & 15,2 & $\mathrm{a}$ & 13,8 & $a b$ & 11,2 & $\mathrm{a}$ & 44 \\
\hline Piper nigrum (L.) & 19,2 & a & 17,0 & $\mathrm{a}$ & 15,9 & a & 12,4 & a & 38 \\
\hline Dipteryx odorata (Aubl.) Forsyth f. & 19,7 & $\mathrm{a}$ & 17,3 & $\mathrm{a}$ & 15,6 & a & 12,6 & a & 37 \\
\hline Theobroma cacao (L.) & 15,6 & $a b$ & 14,5 & $\mathrm{a}$ & 14,6 & $\mathrm{a}$ & 13,4 & $\mathrm{a}$ & 33 \\
\hline
\end{tabular}

Médias seguidas de letras iguais na mesma coluna não diferem entre si pelo teste de Tukey a 5\% de significância.

As leguminosas gliricídia e feijão de porco apresentaram as maiores perdas de massa durante todos os tempos de coleta no período mais chuvoso do ano (período 1). Paula et al. (2015) também observaram que a decomposição da gliricídia foi ligeiramente mais lenta durante a estação seca, devido, provavelmente, às condições climáticas associadas a menores precipitações pluviométricas durante esse período. Estudos realizados por Leite et al. (2010), Pacheco et al. (2011) e Torres et al. (2014) comprovaram a influência da precipitação pluvial sobre a velocidade de decomposição dos resíduos, onde se destaca que a decomposição aumenta paralelo ao aumento da precipitação e diminuem no período seco do ano.

O guandú, apesar de ser uma leguminosa utilizada para adubação verde, mostrou uma decomposição similar às das espécies perenes consideradas de interesse econômico nos dois periodos, o que confere a esta espécie uma característica distinta das demais desta mesma categoria analisadas neste estudo. Ressalta-se que a massa remanescente do guandú, ao final de 120 dias, para os períodos 1 e 2 , foi de $38 \%$ e $56 \%$ respectivamente. A partir desses resultados, espera-se que em períodos com maior 
pluviosidade, como o período 1, o guandú possa devolver ao solo uma carga nutricional mais efetiva, por outro lado, em períodos menos chuvosos, esta espécie passa a ser mais eficaz em promover a cobertura do solo. Em estudo realizado por Belo et al. (2012) também observaram que o feijão guandú apresentou taxa de decomposição mais lenta com relação a outras leguminosas, em especial do feijão de porco.

$\mathrm{O}$ uso de espécies leguminosas, principalmente as consideradas adubações verdes, objetiva melhorar as condições de disponibilidade nutricional dentro do sistema no qual estão inseridas, auxiliando na recuperação e/ou aumento das propriedades físicas, químicas e biológicas do solo (CARDOSO et al., 2014). Destaca-se ainda que as leguminosas apresentam mecanismos que conferem a essas espécies alta capacidade de fixação de nitrogênio e agilidade na produção de biomassa. Por outro lado, a decomposição de matéria seca dessas espécies sobre o piso agroflorestal mantém o solo coberto da mesma forma que aumenta $o$ teor de matéria orgânica, diminuindo a evapotranspiração (LEITE et al., 2010; GIONGO et al., 2011; SILVA et al., 2014).

A Figura 2 demonstra o incremento da decomposição foliar das espécies, em que se verifica que a perda de massa foi contínua em ambos os períodos.

Figura 2. Resíduo foliar remanescente por espécie em função do tempo em cada período avaliado. Em que: (A) cacau, (B) cumaru, (C) pimenta, (D) guandú, (E) feijão-de-porco e (F) gliricídia.
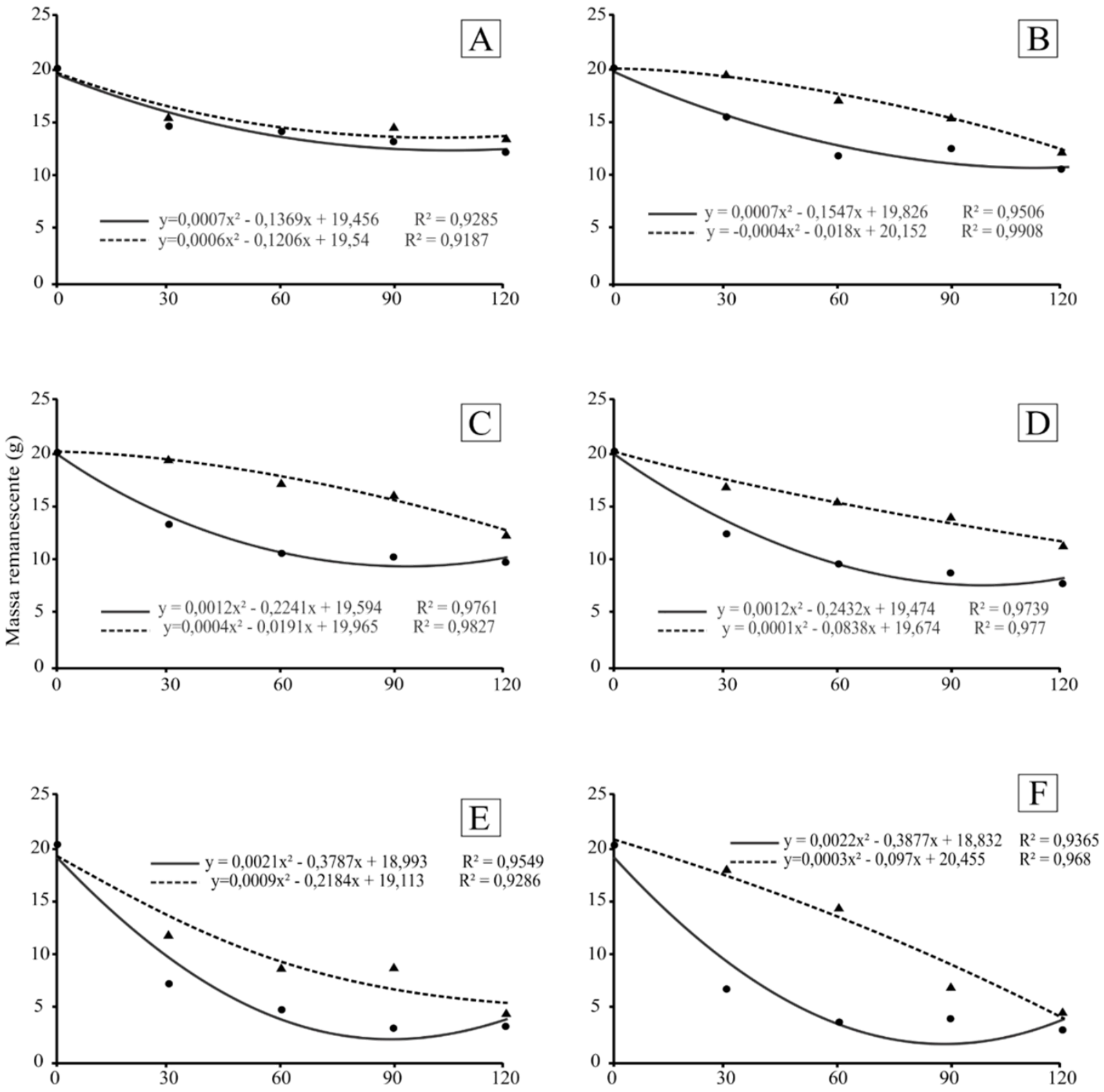

Tempo (dias) 
A Figura 2 demonstra que no período considerado menos chuvoso (período 2) a perda de massa foi mais lenta nos primeiros $60-90$ dias ( 27 a $56 \%$ de perda), em que os índices pluviométricos mensais do local foram críticos (variando de 5 a $11 \mathrm{~mm}$ para esses dias). O contrário foi revelado no período 1 , em que a decomposição foi mais rápida nos primeiros 90 dias (34 a $80 \%$ perda), tendendo a diminuir aos 120 dias, em que foi registrada a diminuição da incidência de chuvas.

A partir da visualização da projeção gráfica das curvas de decomposição, nota-se que o cacau apresentou comportamento semelhante em ambos os períodos, diferentemente das demais espécies avaliadas, sendo a espécie que menos decompôs durante os tempos de estudo. Esses resultados permitem inferir que a biomassa foliar desta espécie apresenta resistência às condições ambientais expostas, aliada ao tamanho e à composição foliar. Embora o cacau seja uma espécie importante para a consorciação, visando os aspectos econômicos e sociais e, apesar de ter um potencial de produção de biomassa, a quantidade de resíduos orgânicos na superfície do solo provenientes da desfolha natural desta espécie é mínima, sendo maior apenas quando são efetuadas as podas do cacaueiro (COTTA et al., 2008), o que determina a dependência da espécie a insumos externos para a sua manutenção. Estudos apontam que em condições naturais a queda das folhas de cacau e a incorporação de biomassa ao solo são influenciadas pelas condições em que os exemplares estão inseridos como a disponibilidade de água, a interação soloplanta-atmosfera e o grau de sombreamento no ambiente de cultivo (BALIGAR et al., 2008; KÖHLER et al., 2009; PAMPONET et al., 2012).

As diferenças demonstradas sobre a dinâmica da decomposição foliar dessas espécies mostram que o processo de decomposição não está somente atrelado a fatores de sazonalidade climatológica, mas também às características morfofisiológicas. A composição química foliar, por exemplo, é um fator determinante para esse processo, onde a relação $\mathrm{C} / \mathrm{N}$ é um indicador relevante à explicação sobre a velocidade de decomposição da matéria orgânica, considerando que o tempo de decomposição é proporcional à relação (GIACOMINI et al., 2003; HOLANDA et al., 2015). De acordo com Doneda (2010) e Pedra et al. (2012), as leguminosas dispõem de menor relação $\mathrm{C} / \mathrm{N}$, o que aumenta a sua taxa de decomposição, pressupondo que o processo de mineralização de nutrientes será maior que a capacidade de imobilização. O contrário ocorre com as espécies de interesse comercial (cacau, pimenta e cumaru), que dispõem de um tecido foliar mais resistente com relação $\mathrm{C} / \mathrm{N}$ maior.

Os resultados da perda de massa foliar também podem estar direcionados ao tamanho da área foliar de cada espécie, considerando que as espécies de interesse econômico possuem o tamanho de suas folhas maiores que as das leguminosas, que dispõem de uma área foliar menor, ocasionando maior superfície específica disponível. Cunha Neto et al. (2013) dispõe que as tipologias de folhagens com menor área facilitam a ação da mesofauna do solo e, consequentemente, aceleram o processo de decomposição e ciclagem nutricional.

Pode-se observar (Figura 2) que algumas espécies apresentaram elevação na média da massa remanescente em alguns tempos de coleta (período 1: cumaru e gliricídia aos 90 dias e feijão-de-porco aos 120 dias; período 2: cacau e feijão-de- porco aos 90 dias), o que, embora representem uma baixa variação (0,02 a 0,64 g), elevou levemente a média. Essa alteração pode ter ocorrido por fatores ambientais in loco como a presença de partículas de solo aderidas ao material foliar contido nos litter bags. Este material é agregado ao tecido foliar durante a ocorrência de chuvas e, dependendo das condições de decomposição em que este se encontra, são de difícil remoção no momento da limpeza para pesagem (SOUTO et al., 2013).

Consideram-se ainda a disposição e coleta aleatória das bolsas em campo e as condições microclimáticas e edáficas do local como fatores de intervenção no resultado do peso de massa remanescente. O posicionamento da bolsa em um local mais ou menos sombreado ou a influência maior ou menor da ação de microrganismos por conta das ações de temperatura e umidade podem intervir na velocidade de decomposição, pois, como explicitado por alguns autores (MARQUES et al., 2008; SOUSA NETO et al., 2011; HOLANDA et al., 2015), as atividades decompositoras sofrem forte influência dos fatores ambientais, a citar, temperatura e umidade.

A Tabela 3 expõe o coeficiente de decomposição (k) e a projeção do tempo de meia-vida (t1/2), organizada a partir do maior valor de $\mathrm{k}$ das espécies por período. Observa-se que as equações utilizadas para estimar a decomposição das espécies refletem verdadeiramente de forma aproximada os dados reais obtidos em campo. As leguminosas gliricídia, feijão-de-porco e guandú foram as espécies que apresentaram os valores de $\mathrm{k}$ mais elevados em ambos os períodos, com os valores variando entre 0,0277 a 0,0104 e 0,0124 a 0,0047 para os períodos 1 e 2 , respectivamente. Valores divergentes a estes foram relatados por Silva et al. (2008) ao avaliar a decomposição de plantas visando o uso para adubação verde em Seropédica - RJ, onde a espécie gliricídia, por exemplo, apresentou $\mathrm{k}=0,033$ e $\mathrm{t} 1 / 2=21$ dias. A diferença de comportamento da decomposição das espécies para diferentes regiões vai além do fator tipo de solo, mas também pela qualidade do microambiente (interação entre fatores físicoquímicos e a biota decompositora) ao qual o material foliar está exposto (GAMA-RODRIGUES et al., 2003).

Contudo, é relevante expor que, ao contrário das leguminosas, as espécies de interesse econômico obtiveram $\mathrm{k}$ menor, sendo de 0,0081 a 0,0049 para o período 1 e 0,0040 a 0,0031 para o período 2 . Considerando os valores de $t_{1 / 2}$, essas espécies levarão em média de um a cinco meses para decompor $50 \%$ de sua massa em condições relativas ao período 1 . Já para o período 2, esse tempo é duplicado para uma variação de dois a oito meses.

De acordo com Souza e Piña-Rodrigues (2013), modelos de SAFs combinados com leguminosas apresentam maior desenvolvimento das espécies arbóreas consorciadas. Assim, considerando as taxas de decomposição de leguminosas e atrelando seu uso e contribuição dentro de sistemas integrados, pressupõe-se que áreas com a presença destas espécies tendem a possuir uma ciclagem de nutrientes mais eficaz, com maior velocidade de decomposição da serapilheira, ocasionando agilidade na liberação de nutrientes para o solo e absorção dos mesmos pelas plantas (CUNHA NETO et al., 2013). 
Taxa de decomposição foliar de espécies utilizadas em sistemas agroflorestais.

Tabela 3. Coeficiente de decomposição obtido pelo ajuste do modelo exponencial e tempo de meia-vida da fração foliar.

\begin{tabular}{|c|c|c|c|c|}
\hline \multirow{2}{*}{ Espécies } & \multicolumn{4}{|c|}{ Parâmetros } \\
\hline & $\mathrm{k}$ & $\mathrm{r}^{2}$ & EPE & $\mathrm{t}_{1 / 2}$ (dias) \\
\hline \multicolumn{5}{|c|}{ Período 1 (abril a agosto) } \\
\hline Gliricidia sepium (Jacq.) Kunth ex Walp. & 0,0277 & 0,96 & 0,0023 & 25 \\
\hline Canavalia ensiformis (L.) DC. & 0,0253 & 0,96 & 0,0021 & 27 \\
\hline Cajanus cajan (L.) Huth & 0,0104 & 0,91 & 0,0008 & 67 \\
\hline Piper nigrum (L.) & 0,0081 & 0,81 & 0,0008 & 86 \\
\hline Dipteryx odorata (Aubl.) Forsyth f. & 0,0059 & 0,91 & 0,0004 & 117 \\
\hline Theobroma cacao (L.) & 0,0049 & 0,78 & 0,0005 & 141 \\
\hline \multicolumn{5}{|c|}{ Período 2 (setembro a janeiro) } \\
\hline Canavalia ensiformis (L.) DC. & 0,0124 & 0,95 & 0,0008 & 56 \\
\hline Gliricidia sepium (Jacq.) Kunth ex Walp. & 0,0090 & 0,87 & 0,0011 & 77 \\
\hline Cajanus cajan (L.) Huth & 0,0047 & 0,92 & 0,0003 & 149 \\
\hline Theobroma cacao (L.) & 0,0040 & 0,54 & 0,0007 & 173 \\
\hline Piper nigrum (L.) & 0,0032 & 0,93 & 0,0002 & 220 \\
\hline Dipteryx odorata (Aubl.) Forsyth f. & 0,0031 & 0,93 & 0,0002 & 226 \\
\hline
\end{tabular}

Em que: $\mathrm{k}$ : constante da decomposição; $\mathrm{r}^{2}$ : coeficiente de determinação do ajuste para a estimativa do $\mathrm{k}$; EPE: Erro-padrão da estimativa de $\mathrm{k} ; \mathrm{t}_{1 / 2}$ : tempo de meia vida do material foliar.

\section{CONCLUSÕES}

As espécies para a prática de adubação verde foram as que obtiveram maiores taxa de decomposição, para os dois períodos estudados. As espécies Gliricídia e feijão de porco são recomendadas para retorno de nutrientes em curto prazo de tempo.

A pimenta do reino se mostrou eficiente no processo de ciclagem de nutrientes.

A precipitação pluvial influencia marcadamente a decomposição da serapilheira foliar.

A disposição dos litter bags no campo é um fator de grande influência na perda de massa foliar.

\section{AGRADECIMENTO}

À Universidade Federal do Oeste do Pará (UFOPA), por meio da Diretoria de Pesquisa, vinculada à Pró-Reitoria de Pesquisa, Pós-graduação e Inovação Tecnológica (Proppit), pelo fomento a esta pesquisa através do Edital 08/2017 PROPPIT/UFOPA do Programa de Fomento a Trabalhos de Conclusão de Curso (PROTCC/UFOPA).

\section{REFERÊNCIAS}

BALIGAR, V. C.; BUNCE, J. A.; MACHADO, R. C. R.; ELSON, M. K. Photosynthetic photon flux density, carbono dioxide concentration, and vapour pressure deficit effects on photosynthesis in cacao seedlings. Photosynthetica, v. 46, p. 216-221, 2008.

BARRADAS, C. A. A. Adubação Verde. 25.ed. Niterói: Rio Rural, 2010. 10p.

BAUER, D.; SANTOS, E. L.; SCHMITT, J. L. Avaliação da decomposição de serapilheira em dois fragmentos de Caatinga no Sertão Paraibano. Pesquisas, Botanica, v. 69, p. 307-318, 2016.
BELO, E. S.; TERRA, F. D.; ROTTA, L. R.; VILELA, L. A.; PAULINO, H. B.; SOUSA, E. D.; VILELA, L. A. F.; CARNEIRO, M. A. C. Decomposição de diferentes resíduos orgânicos e efeito na atividade microbiana em um latossolo vermelho de cerrado. Gl. Sci Technol., v. 5, n. 3, p. 107-116, 2012.

CABIANCHI, G. M. Ciclagem de nutrientes via serapilheira em um fragmento ciliar do rio Urupá, Rondônia. 2010. 101f. Dissertação (Mestrado em Ciência) Universidade de São Paulo, Piracicaba. 2010.

CARDOSO, R. A.; BENTO, A. S.; MORESKI, H. M.; GASPAROTTO, F. Influência da adubação verde nas propriedades físicas e biológicas do solo e na produtividade da cultura de soja. Semina: Ciências Biológicas e da Saúde, v. 35, p. 51-60, 2014.

COSTA, C. C. A.; CAMACHO, R. G. V; MACEDO, I. D.; SILVA, P. C. M. Análise comparativa da produção de serrapilheira em fragmentos arbóreos e arbustivos em área de caatinga na Flona de Açu - RN. Revista Árvore, v. 2, n. 34, p. 259-265, 2010.

COTTA, M. K.; JACOVINE, L. A. G.; PAIVA, H. N. de; SOARES, C. P. B.; FILHO, A. de C. V.; VALVERDE, S. R. Quantificação de biomassa e geração de certificados de emissões reduzidas no consórcio seringueira-cacau. Revista Árvore, Viçosa, v. 32, n. 6, p. 969-978, 2008.

CUNHA NETO, F. V.; LELES, P. S. S.; PEREIRA, M. G.; BELlUMATH, V. G. H.; ALONSO, J. M. Acúmulo e decomposição da serapilheira em quatro formações florestais. Ciência Florestal, Santa Maria, v .23, n. 3, p. 379-387, 2013.

CUNHA, G. M.; TINTORI, J. L.; MOREIRA, G. R.; SILVA, D. M.; PIVATTO, G. L. Produção de serapilheira e ciclagem de nutrientes em Sistema Agroflorestal com cafeeiro no Sul do 
Estado do Espírito Santo. Cadernos de Agroecologia, v. 13, n 1, 2018.

DONEDA, A. Plantas de cobertura de solo consorciadas e em cultivo solteiro: decomposição e fornecimento de nitrogênio ao milho. 2010. 81f. Dissertação (Mestrado em Ciência do Solo) Universidade Federal de Santa Maria, Santa Maria. 2010.

EWERT, M.; VENTURIERI, G. A.; STEENBOCK; W.; SEOANE, C. E. S. Sistemas agroflorestais multiestrata e a legislação ambiental brasileira: desafios e soluções. Desenvolv. Meio Ambiente, v. 36, p. 95-114, 2016.

FERREIRA, J. D. Análise do plano processo na urbanização de cidades do Baixo Amazonas: o caso de Santarém - Brasil. 2011. 118f. Dissertação (Mestrado em Desenvolvimento e Meio Ambiente Urbano) Universidade da Amazônia, Belém. 2011.

FONTES, A. G. Ciclagem de nutrientes em sistemas agroflorestais de cacau no sul da Bahia. 2006. 116f. Tese (Doutorado em Ciências e Tecnologias Agropecuárias) Universidade Estadual do Norte Fluminense Darcy Ribeiro, Rio de Janeiro. 2006.

GAMA-RODRIGUES, A. C.; BARROS, N. F.; SANTOS, M. L. Decomposição e liberação de nutrientes do folhedo de espécies florestais nativas em plantios puros e mistos no sudeste da Bahia. Revista Brasileira de Ciências Solo, v. 27, p. 1021-1031, 2003.

GIACOMINI, S. J.; AITA, C.; VENDRUSCOLO, E. R. O.; CUBILLA, M.; NICOLOSO, R. S.; FRIES, M. R. Matéria seca, relação $\mathrm{C} / \mathrm{N}$ e acúmulo de nitrogênio, fósforo e potássio em misturas de plantas de cobertura de solo. Revista Brasileira de Ciência do Solo, v. 27, n. 2, p. 325-334, 2003.

GIONGO, V.; MENDES, A. M. S.; CUNHA, T. J. F.; GALVÃO, S. R. S. Decomposição e liberação de nutrientes de coquetéis vegetais para utilização no semiárido brasileiro. Revista Ciência Agronômica, v. 42, p. 611- 618, 2011.

HOLANDA, A. C.; FELICIANO, A. L. P.; MARAGON, L. C.; FREIRE, F. J.; HOLANDA, E. M. Decomposição da serapilheira foliar e respiração edáfica em um Remanescente de caatinga na paraíba. Revista Árvore, v. 39, n. 2, p. 245-254, 2015.

IDESP. Estatísticas Municipal de Santarém. 2014. Disponível em: <http://www.idesp.pa.gov.br/pdf/statisticaMunicipal>. Acessado em: 16 de fevereiro de 2018.

KÖHLER, M.; DIERICK, D.; SCHWENDENMANN, L.; HÖLSCHER, D. Water use characteristics of cacao and Gliricidia trees in an agroforest in Central Sulawesi. Ecohydrology, v. 2, p. 520-529, 2009.

LEITE, L. F. C.; FREITAS, R. C. A.; SAGRILO, E.; GALVÃO, S. R. S. Decomposição e liberação de nutrientes de resíduos vegetais depositados sobre Latossolo Amarelo no Cerrado Maranhense. Revista Ciência Agronômica, v. 41, n. 1, p. 29-35, 2010.
LOPES, M. N. G.; SOUZA, E. B. de; FERREIRA, D. B. da S. Climatologia regional da precipitação no Estado do Pará. Revista Brasileira de Climatologia, v. 12, p. 84-102, 2013.

MARQUES, M. F. O.; GUSMÃO, L. F. P.; MAIA, L. C. Riqueza de espécies de fungos conidiais em duas áreas de Mata Atlântica no Morro da Pioneira, Serra da Jibóia, BA, Brasil. Acta botânica brasílica, v. 22, n. 4, p. 954-961, 2008.

PACHECO, L. P.; LEANDRO, W. M.; MACHADO, P. L. O. A.; ASSIS, R. L.; COBUCCI, T.; MADARI, B. E.; PETTER, F. A. Produção de fitomassa e acúmulo e liberação de nutrientes por plantas de cobertura na safrinha. Pesquisa Agropecuária Brasileira, v. 46, n. 1, p. 17-25, 2011.

PAMPONET, B. M.; OLIVEIRA, A. da S.; MARINHO, L. B.; VELLAME, L. M.; PAZ, V. P. da S. Efeitos das diferenças térmicas naturais na estimativa do fluxo de seiva pelo método de granier em cacaueiro a pleno sol. Irriga, Edição Especial, p. 120132, 2012.

PAULA, P. D.; CAMPELLO, E. F. C.; GUERRA, J. G. M.; SANTOS, G. A.; RESENDE, A L. Decomposição das podas das leguminosas arbóreas Gliricidia sepium e Acacia angustissima em um sistema agroflorestal. Ciência Florestal, v. 25, n. 3, p. 791$800,2015$.

PEDRA, W. N.; PEDROTTI, A.; SILVA, T. O.; MACEDO, F. L. de; GONZAGA, M. I. S. Estoques de carbono e nitrogênio sob diferentes condições de manejo de um Argissolo Vermelho Amarelo, cultivado com milho doce nos tabuleiros costeiros de Sergipe. Semina: Ciências Agrárias, v. 33, n. 6, p. 2075-2089, 2012.

ROSSI, C. Q.; PEREIRA, M. G.; GIÁCOMO, S. G.; BETTA, M.; POLIDORO, J. C. Decomposição e liberação de nutrientes da palhada de braquiária, sorgo e soja em áreas de plantio direto no cerrado goiano. Semina: Ciências Agrárias, Londrina, v. 34, n. 4, p. 1523-1534, 2013.

SCHUMACHER, M. V.; CORRÊA, R. S.; VIERA, M.; ARAÚJO, E. F. Produção e decomposição de serapilheira em um povoamento de Eucalyptus urophyllax Eucalyptus globulusmaidenii. Cerne, v. 19, n. 3, p. 501-508, 2013.

SCORIZA, R. N.; PEREIRA, M. G.; PEREIRA, G. H. A.; MACHADO, D. L.; SILVA, E. M. R. da. Métodos para coleta e análise de serrapilheira aplicados à ciclagem de nutrientes. Floresta e Ambiente, v. 2, n. 2, p. 01-18, 2012.

SILVA, G. T. A.; MATOS, L. V.; NÓBREGA, P. de O.; CAMPELlO, E. F. C.; RESENDE, A. S. de. Chemical composition and decomposition rate of plants used as green manure. Scientia Agricola, v. 65, n. 3, p. 298-305, 2008.

SILVA, H. F.; BARRETO, P. A. B.; SOUSA, G. T. de O.; AZEVEDO, G. B.; GAMA-RODRIGUES, E. F.; OLIVEIRA, F. G. R. B. Decomposição de serapilheira foliar em três sistemas 
florestais no Sudoeste da Bahia. Revista Brasileira de Biociências, Porto Alegre, v.12, n. 3, p. 164-172, 2014.

SOUSA NETO, E.; CARMO, J. B.; KELLER, M.; MARTINS, S. C.; ALVES, L. F.; VIEIRA, S. A.; PICCOLO, M. C.; CAMARGO, P.; COUTO, H. T. Z.; JOLY, C. A.; MARTINELLI, L. A. Soil-atmosphere exchange of nitrous oxide, methane and carbon dioxide in a gradient of elevation in the coastal Brazilian Atlantic forest. Biogeosciences, v. 8, p. 733-742, 2011.

SOUSA, W. A. de; VIEIRA, T. A. Sistemas agroflorestais: uma análise bibliométrica da produção científica de revistas brasileiras no período de 2005 a 2015 . Revista Espacios, v. 38, n. 36, 2017.

SOUTO, P. C.; SOUTO, J. S.; SANTOS, R. V. do; BAKKE, I. A.; SALES, F. das C. V.; SOUZA, B. V. de. Taxa de decomposição da serapilheira e atividade microbiana em área de caatinga. Cerne, Lavras, v. 19, n. 4, p. 559-565, 2013.

SOUZA, C. M. de; PIRES, F. R.; PARTELLI, F. L.; ASSIS, R. L. de. Adubação verde e rotação de culturas - Série Didática. 1.ed. Viçosa: Editora UFV, 2012. 108p.

SOUZA, M. C. S. de; PIÑA-RODRIGUES, F. C. M. Desenvolvimento de espécies arbóreas em sistemas agroflorestais para recuperação de áreas degradadas na floresta ombrófila densa, Paraty, RJ. Revista Árvore, v. 37, n. 1, p. 8998, 2013.

THOMAS, R. J.; ASAKAWA, N. M. Decomposition of leaf litter from tropical forage grasses and legumes. Soil Biology and Biochemistry, v. 25, n. 10, p. 1351-1361, 1993.

TORRES, J. L. R.; SILVA, M. G. S.; CUNHA, M. A.; VALLE, D. X. P.; PEREIRA, M. G. Produção de fitomassa e decomposição de resíduos culturais de plantas de coberturas no cultivo da soja em sucessão. Revista Caatinga, v. 27, n. 3, p. 247 $-253,2014$.

VIEIRA, M.; Schumacher, M. V.; ARAUJO, E. F. Disponibilização de nutrientes via decomposição da serapilheira foliar em um plantio de Eucalyptus urophylla $\times$ Eucalyptus globulus. Floresta Ambient., v. 21, n. 3, p. 307 - 3015, 2014.

WUTKE, E. B.; CALEGARI, A.; WILDNER, L. do P. Espécies de adubos verdes e plantas de cobertura e recomendações para seu uso. In: FILHO, O. F. de L.; AMBROSANO, E. J.; ROSSI, F; CARLOS, J. A. D. (eds.). Adubação verde e plantas de cobertura no Brasil. Fundamentos e Práticas - Volume I. Brasília: EMBRAPA, 2014. cap.3, p. 59-168. 